\title{
KELANGSUNGAN HIDUP DAN PERTUMBUHAN BENIH IKAN PATIN SIAM (Pangasius hypophthalmus) PADA SUHU MEDIA PEMELIHARAAN YANG BERBEDA
}

\section{The Survival Rate and Growth of Siamese Catfish (Pangasius hypophthalmus) in Temperature of Different Maintenance Media}

\author{
Goriang Putra Wangni ${ }^{1}$, Sugeng Prayogo ${ }^{2}$, dan Sumantriyadi ${ }^{1}$ \\ 1) Program Studi Ilmu Perikanan Fakultas Perikanan Universitas PGRI Palembang \\ 2) Balai Karantina Ikan, Pengendalian Mutu dan Keamanan Hasil Perikanan Palembang \\ Email : sumantriyadi@ymail.com
}

\begin{abstract}
Abstrak
Ikan patin siam (Pangasius hypophthalmus) berpotensi untuk dibudidayakan namun dalam proses budidayanya terdapat beberapa kendala yaitu ketersediaan benih yang akan ditebar. Ini disebabkan oleh tingginya kematian pada saat stadia larva ke fase calon benih akibat perubahan suhu lingkungan perairan. Penelitian ini bertujuan untuk mengetahui suhu yang baik bagi kelangsungan hidup dan pertumbuhan benih ikan Patin Siam (Pangasius hypophthalmus). Penelitian dilaksanakan di Balai Benih Ikan Lokal Tanjung Putus Ogan Ilir. Ikan uji yang digunakan adalah benih ikan Patin Siam yang berumur 6 hari dengan panjang rata-rata sebesar $1,30 \mathrm{~cm}$ dan berat rata-rata sebesar 0,02 gram. Benih ikan dipelihara di akuarium berukuran 50 x 40 × $50 \mathrm{~cm}$. Penelitian ini menggunakan metode eksperimen dengan menggunakan Rancangan Acak Lengkap (RAL), terdiri 4 taraf perlakuan dengan 3 kali ulangan. Hasil penelitian menunjukkan bahwa perlakuan $\mathrm{C}$ (suhu media pemeliharaan $30 \pm 0,8^{\circ} \mathrm{C}$ ) menghasilkan SR terbaik dari perlakuan lain yaitu sebesar $86,5 \%$ dengan pertumbuhan panjang rata-rata sebesar $4,13 \mathrm{~cm}$ dan berat rata-rata sebesar 1,39 gram. Perlakuan D (suhu media pemeliharaan $32 \pm 0,8^{\circ} \mathrm{C}$ ) menghasilkan SR sebesar $83,3 \%$, dengan pertumbuhan panjang rata-rata sebesar 3,65 cm dan berat rata-rata sebesar 1,05 gram. Perlakuan B (suhu media pemeliharaan $28 \pm 0,8^{\circ} \mathrm{C}$ ) menghasilkan SR sebesar 75,7 \%, dengan pertumbuhan panjang rata-rata sebesar $3,39 \mathrm{~cm}$ dan berat rata-rata sebesar 0,87 gram. Sedangkan perlakuan A (suhu media pemeliharaan $26 \pm 0,8^{\circ} \mathrm{C}$ ) menghasilkan nilai yang paling rendah diantara perlakuan lain. Perlakuan A menghasilkan SR sebesar 65,7 \%, pertumbuhan panjang rata-rata sebesar 3,00 dan berat rata-rata sebesar 0,62 gram. Hasil penelitian menunjukkan bahwa perlakuan $\mathrm{C}$ mempunyai kualitas air yaitu suhu berkisar antara 29,5-30,8, ${ }^{\circ} \mathrm{C}$ pH 6,07-6,10, DO 2,05-3,06 mg/l. Hasil pengamatan kualitas air selama penelitian masih dalam batas toleransi untuk benih ikan Patin Siam.
\end{abstract}

Kata Kunci: Ikan Patin Siam, Suhu, Kelangsungan Hidup, Pertumbuhan

\begin{abstract}
This study was aimed to determine the temperature of both the survival and growth of fish seed Siamese cat fish (Pangasius hypophthalmus). This study was conducted in the Local Fish Seed Cape Disconnect Ogan Ilir. Test fish used are seed Siamese fish 6 days with an average length of $1.30 \mathrm{~cm}$ and an average weightof 0.02 grams. Seeds kept in aquarium fish measuring $50 \times 40 \times 50 \mathrm{~cm}$. The method used is an experimental method using a Completely Randomized Design (CRD), treatment comprised 4 levels with 3 replications. The results showed that the $C$ treatment (maintenance medium temperature $30 \pm 0.8{ }^{\circ} \mathrm{C}$ ) produce the best SRof an other treatment that is equal to $86.5 \%$ with growth in average length of $4.13 \mathrm{~cm}$ and an average weight of 1.39 grams. $D$ treatment (maintenance medium temperature $32 \pm 0.8{ }^{\circ} \mathrm{C}$ ) resulted in $S R$ by 83.3\%, with growth in the average length of $3.65 \mathrm{~cm}$ and an average weight of 1.05 grams. Treatment B (medium temperature of $28 \pm 0.8^{\circ}$ C maintenance) generates SR75.7\%, with growth in the average length of $3.39 \mathrm{~cm}$ and an average weight of $0.87 \mathrm{grams}$. While the A treatment (maintenance medium temperature $26 \pm 0.8^{\circ} \mathrm{C}$ ) resulted in the lowest value among the other treatments. A treatment resulted in SR of 65.7\%, growth inaverage length of 3.00 an dan average weight of 0.63 grams. The results showed that treatment $C$ have water quality that is temperature ranged from 29.5 to $30.8^{\circ} \mathrm{C}, \mathrm{pH}$ 6.07 to 6.10, DO2.05 to $3.06 \mathrm{mg} / \mathrm{l}$. The observation of water quality measured during the study are still with in tolerance limits for the seed Siamese cat fish.
\end{abstract}

Keyword : Siamese catfish, Temperature, Survival Rate, Growth 


\section{PENDAHULUAN}

Ikan patin siam berpotensi untuk dibudidayakan karena memiliki laju pertumbuhan yang tinggi. Meskipun laju pertumbuhannya tinggi dan mudah dibudidayakan, namun dalam proses budidayanya terdapat beberapa kendala, antara lain kendala dalam ketersediaan benih yang akan ditebar. Hal ini disebabkan oleh tingginya kematian pada saat di stadia larva. Djarijah (2001) menyatakan bahwa tahap pemeliharaan larva untuk budidaya ikan patin sangat rentan, karena tahap larva sangat sensitif terhadap perubahan lingkungan perairan.

Pemeliharaan larva Pangasius sp yang baik diperoleh dalam rentang suhu $26-31{ }^{0} \mathrm{C}$, suhu yang tinggi menyebabkan rendahnya pertumbuhan biota perairan, demikian juga apabila suhu rendah. Hal ini menyebabkan proses pencernaan makanan pada ikan berlangsung lambat sehingga akan mempengaruhi nafsu makan ikan. Perubahan mendadak akibat naik turunnya suhu secara tiba tiba dapat menyebabkan ikan sulit beradaptasi dan mengalami stress berkelanjutan yang dapat berakhir dengan kematian (Hernowo, 2001 dalam Djarijah 2001). Selain itu, suhu juga merupakan salah satu faktor eksternal yang mempengaruhi pertumbuhan ikan (Huet, 1971). Berdasarkan hal tersebut, maka perlu dilakukan suatu penelitian untuk mengetahui suhu yang terbaik bagi kelangsungan hidup dan pertumbuhan benih ikan patin siam.

\section{METODE PENELITIAN}

\section{Waktu dan Tempat Penelitian}

Penelitian ini dilaksanakan di Balai Benih Ikan Lokal Tanjung Putus Desa Tanjung Pering Kecamatan Indralaya Utara Kabupaten Ogan Ilir.

\section{Metode Penelitian}

Penelitian ini menggunakan Rancangan Acak Lengkap (RAL) terdiri atas 4 taraf perlakuan dengan masig-masing dilakukan 3 kali pengulangan. Perlakuan yang digunakan adalah :
$\mathrm{A}=$ Suhu Media Pemeliharaan $26 \pm 0,8{ }^{\circ} \mathrm{C}$

$\mathrm{B}=$ Suhu Media Pemeliharaan $28 \pm 0,8^{\circ} \mathrm{C}$

$\mathrm{C}=$ Suhu Media Pemeliharaan $30 \pm 0,8^{\circ} \mathrm{C}$

$\mathrm{D}=$ Suhu Media Pemeliharaan $32 \pm 0,8{ }^{\circ} \mathrm{C}$

\section{Analisis Data}

a. Pertumbuhan Berat

Perhitungan pertambahan berat dan panjang dilakukan seperti yang di kemukakan (Effendie, 1979)

$$
\begin{array}{ll}
\text { Keterangan : } \\
\mathrm{W} & =\text { Pertambahan berat (gr) } \\
\mathrm{Wt} & =\text { Berat rata-rata ikan pada akhir (gr) } \\
\mathrm{Wo} & =\text { Berat rata-rata ikan pada awal (gr) }
\end{array}
$$

\section{b. Pertumbuhan Panjang :}

$$
\mathbf{T}=\mathbf{L t}-\mathbf{L o}
$$

Keterangan :

$\mathrm{T}=$ Pertambahan panjang $(\mathrm{cm})$

$\mathrm{Lt}=$ Panjang rata-rata ikan pada akhir $(\mathrm{cm})$

Lo $=$ Panjang rata-rata ikan pada awal $(\mathrm{cm})$

c. Kelangsungan Hidup (SR)

Pengamatan kelangsungan hidup menggunakan rumus yang (Effendie, 1979).

$$
\mathbf{S R}=\frac{\mathbf{N t}}{\mathbf{N}_{\mathrm{o}}} \times 100 \%
$$

Keterangan :

$$
\begin{array}{ll}
\mathrm{SR} & =\text { Derajat kelulusan hidup (\%) } \\
\mathrm{Nt} & =\text { Jumlah pada akhir pemeliharaan (ekor) } \\
\mathrm{No} & =\text { Jumlah pada awal penebaran (ekor) }
\end{array}
$$

\section{d. Kualitas Air}

Parameter kualitas air yang diukur meliputi suhu, $\mathrm{pH}$, dan oksigen terlarut (DO).

Data yang diperoleh dari hasil pengamatan selama penelitian akan dianalisis sidik ragam (ANOVA) pada taraf 5\% dan 1\% (Hanafiah, 1995).

\section{HASIL DAN PEMBAHASAN}

\section{Kelangsungan Hidup Benih}

Hasil kegiatan penelitian diperoleh kelangsungan hidup benih Ikan Patin Siam (Pangasius hypophthalmus) dapat dilihat pada

\section{Gambar 1.}

Kelangsungan Hidup

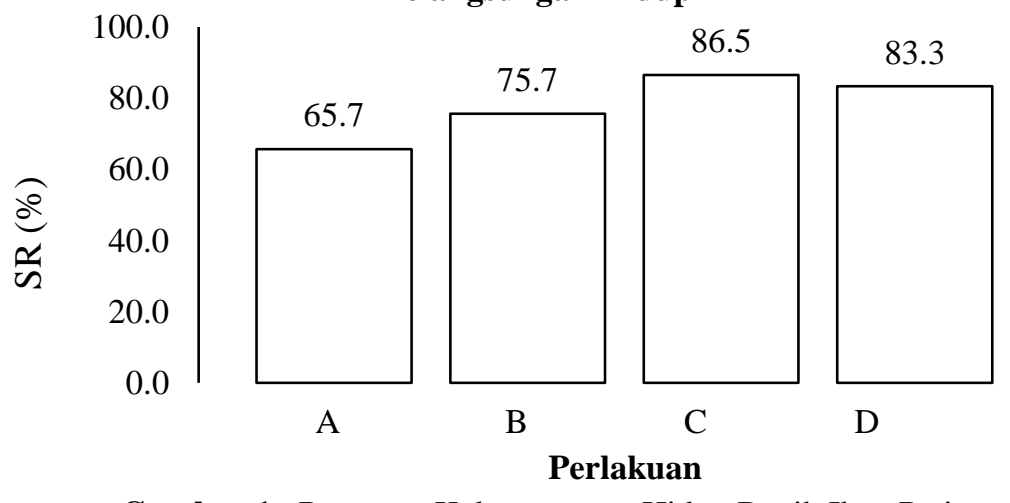

Gambar 1. Rata-rata Kelangsungan Hidup Benih Ikan Patin 
Kelangsungan hidup benih Ikan Patin Siam (Pangasius hypophthalmus) yang tertinggi diperoleh pada perlakuan $\mathrm{C}$ dengan nilai rata-rata sebesar $65,7 \%$, diikuti perlakuan B dengan rata-rata sebesar $75,7 \%$ dan perlakuan D memiliki nilai ratarata sebesar $83,3 \%$. Sedangkan nilai rata-rata yang terendah terdapat pada perlakuan A dengan nilai rata-rata sebesar $65,7 \%$. Selama pemeliharaan benih ikan patin siam (Pangasius hypophthalmus), terdapat perbedaan persentase kelangsungan hidup pada setiap perlakuan. Pada perlakuan A (suhu media pemeliharaan $26 \pm 0,8{ }^{\circ} \mathrm{C}$ ) menghasilkan persentase kelangsungan hidup yang paling rendah yaitu $65,7 \%$.

Dari pengamatan selama 30 hari pemeliharaan umur D 6 hingga umur D 35 benih ikan patin siam, perlakuan A merupakan yang paling banyak mengalami kematian. Hal ini dikarenakan ukuran ikan pada perlakuan A ini masih kecil yang seharusnya sudah melebihi ukuran benih ikan patin siam pada umumnya, dibandingkan dengan benih ikan pada perlakuan yang lainnya. Suhu pada perlakuan A adalah suhu media pemeliharaan yang paling rendah diantara perlakuan yang lain. Ternyata suhu yang rendah dapat mempengaruhi kelangsungan hidup benih ikan, karena suhu perairan yang rendah berdampak terhadap nafsu makan ikan sehingga ketahanan tubuh ikan tersebut melemah dan mudah terserang penyakit hingga mengakibatkan kematian.

Menurut Haris et al (2017), suhu air berhubungan dengan kesehatan ikan berkaitan erat dengan kelangsungan hidup, hanya ikan yang memiliki daya tahan tubuh yang baik dan kesehatannya terjaga yang dapat bertahan hidup. Ikan merupakan hewan berdarah dingin sehingga metabolisme yang berlangsung di dalam tubuh tergantung pada suhu lingkungannya, termasuk kekebalan tubuh. Pada suhu rendah ikan menjadi tidak aktif sering berkumpul atau bergerombol tidak mau berenang dan mengakibatkan berkurangnya imunitas atau kekebalan tubuh, sehingga mudah terserang penyakit jamur atau penyakitparasit sedangkan suhu tinggi dapat mempercepat terjadinya infeksi bakteri.

Suhu yang terlalu rendah untuk pemeliharaan benih ikan patin siam tidak terlalu baik bagi kelangsungan hidup. Pada suhu yang rendah lambat laun ikan tersebut mengalami stress hingga mengakibatkan kematian. Kematian benih ikan patin siam ini disebabkan benih ikan belum mampu beradaptasi dengan baik pada lingkungannya yang baru pada awal pemeliharaan, dimana benih ikan patin siam yang digunakan sebagai hewan uji tersebut adalah benih yang berumur 6 hari.

Persentase kelangsungan hidup semua perlakuan masih dalam batas toleransi, hal ini sesuai menurut BSN, (2000.c), bahwa persentase kelangsungan hidup pemeliharaan benih ikan patin selama 15 hari adalah 50\%, 21 hari sebesar 85\%, dan 30 hari sebesar $80 \%$.

\section{Pertumbuhan Panjang dan Berat Mutlak}

Data rata-rata pertumbuhan panjang selama 30 hari pemeliharaan diperoleh pertumbuhan panjang benih Ikan Patin Siam seperti yang disajikan pada Gambar 2 berikut ini.

\section{Pertumbuhan Panjang}

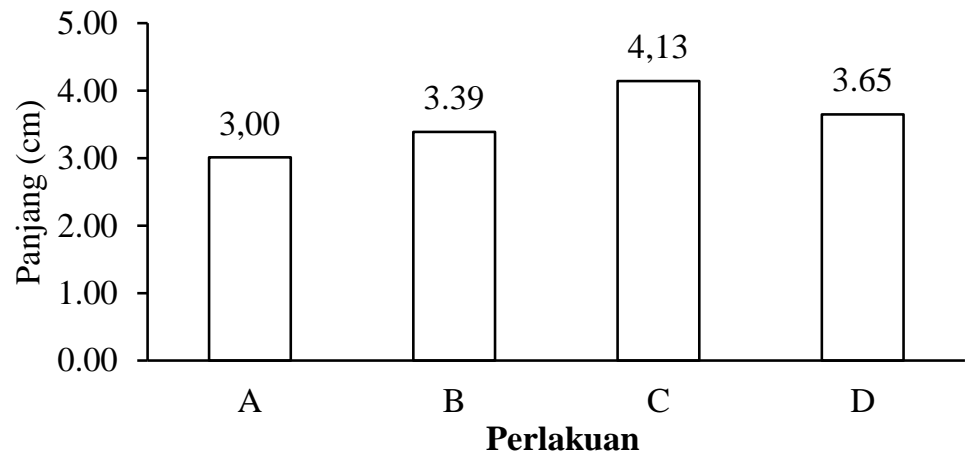

\section{Gambar 2. Panjang Rata-rata Benih Ikan Patin Siam (Pangasius hypophthalmus)}

Dari Gambar 2, diperoleh rata-rata Sedangkan rata-rata pertambahan pertambahan pertumbuhan panjang tertinggi pertumbuhan berat selama 30 hari diperoleh diperoleh pada perlakuan $\mathrm{C}$ dengan nilai $4,14 \mathrm{~cm}$, diikuti oleh perlakuan $\mathrm{D}$ dengan nilai $3,65 \mathrm{~cm}$, selanjutnya diikuti pada perlakuan $\mathrm{B}$ dengan nilai pertumbuhan berat benih Ikan Patin Siam seperti yang disajikan pada Gambar 3 berikut ini. nilai 3,00 . 


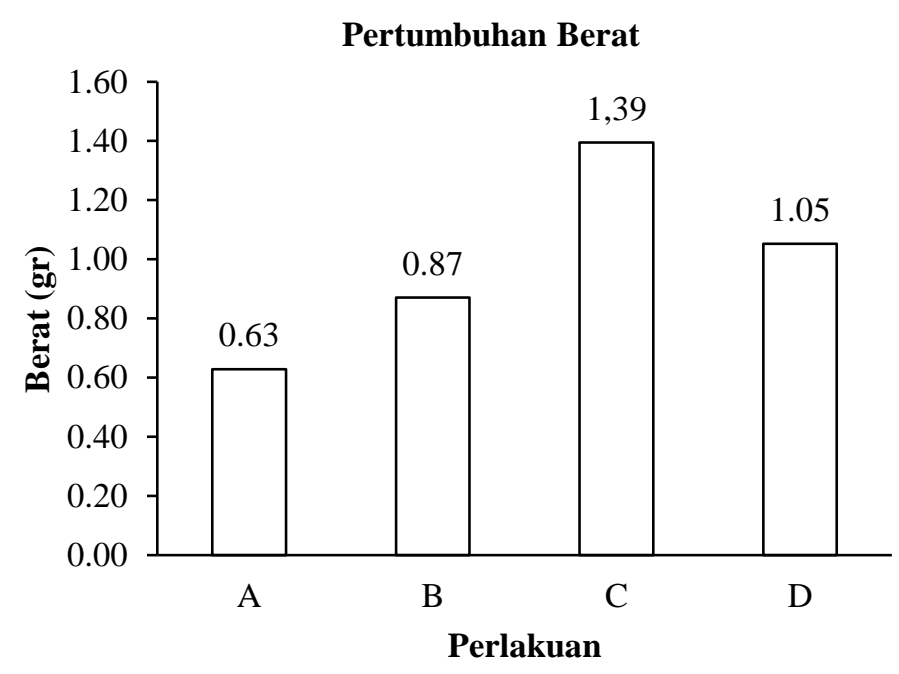

Gambar 3. Pertambahan Berat Rata-rata Benih Ikan Patin Siam (Pangasius hypophthalmus)

Dari Gambar 3 dapat dilihat bahwa nilai pertumbuhan berat mutlak rata-rata benih Ikan Patin Siam (Pangasius hypophthalmus) tertinggi adalah perlakuan $\mathrm{C}$ (suhu media pemeliharaan $30 \pm$ $0,8{ }^{\circ} \mathrm{C}$ ) sebesar 1,39 gram, diikuti oleh perlakuan D (suhu media pemeliharaan $32 \pm 0,8{ }^{\circ} \mathrm{C}$ ) sebesar 1,05 gram, kemudian diikuti perlakuan B (suhu media pemeliharaan $28 \pm 0,8{ }^{0} \mathrm{C}$ ) sebesar 0,87 gram, serta nilai terendah berada pada perlakuan A (suhu media pemeliharaan $26 \pm 0,8{ }^{\circ} \mathrm{C}$ ).

Berdasarkan data hasil dari uji analisis sidik ragam (ANSIRA), diketahui bahwa terdapat pertumbuhan panjang dan berat yang lebih baik pada benih Ikan Patin Siam (Pangasius hypophthalmus) yang diberikan perlakuan suhu media pemeliharaan $30 \pm 0,8^{0} \mathrm{C}$ yaitu perlakuan $\mathrm{C}$, dibandingkan dengan perlakuan $\mathrm{A}$ (suhu media pemeliharaan $26 \pm 0,8^{\circ} \mathrm{C}$ ), perlakuan $\mathrm{B}$ (suhu media pemeliharaan $28 \pm 0,8^{\circ} \mathrm{C}$ ) dan perlakuan $\mathrm{D}$ (suhu media pemeliharaan $32 \pm 0,8^{\circ} \mathrm{C}$ ). Selama pemeliharaan benih ikan Patin Siam selama 30 hari yang dimulai dari umur ikan 6 hari sampai 35 hari telah mendapatkan rata-rata pertumbuhan panjang perlakuan A sebesar $3,00 \mathrm{~cm}$, perlakuan B sebesar $3,39 \mathrm{~cm}$, perlakuan $\mathrm{C}$ sebesar $4,13 \mathrm{~cm}$, dan perlakuan D sebesar $3,65 \mathrm{~cm}$.

Pada perlakuan A dengan suhu media pemeliharaan $26 \quad \pm 0,8 \quad{ }^{0} \mathrm{C}$ menunjukkan pertumbuhan terendah dibandingkan perlakuan yang lain. Lambannya pertumbuhan ikan disebabkan oleh proses pencernaan makanan pada ikan tersebut berlangsung lambat. Suhu pemeliharaan yang rendah juga berdampak pada nafsu makan menjadi berkurang sehingga asupan nutrisi ikan menjadi berkurang. Begitu pula pada perlakuan B (suhu media pemeliharaan $28 \pm 0,8$ ${ }^{0} \mathrm{C}$ ), perlakuan $\mathrm{C}$ (suhu media pemeliharaan 30 $\left.\pm 0,8{ }^{\circ} \mathrm{C}\right)$, dan perlakuan $\mathrm{D}\left(32 \pm 0,8{ }^{\circ} \mathrm{C}\right)$, ada beberapa ikan yang mengalami keterlambatan pertumbuhan, namun tidak sebanyak pada perlakuan A (suhu media pemeliharaan $26 \pm 0,8{ }^{\circ} \mathrm{C}$ ) yang menghasilkan rata-rata pertumbuhan yang paling rendah diantara perlakuan lain.

Pada pengamatan perlakuan A (suhu media pemeliharaan $26 \pm 0,8{ }^{\circ} \mathrm{C}$ ) terlihat benih ikan berenang tidak lincah, dengan warna ikan agak kehitaman disertai dengan ukuran panjang dan berat ikan yang tidak sesuai dengan ukuran sebenarnya berdasarkan umur ikan tersebut. Dalam keadaan stress ikan akan membutuhkan energi yang lebih banyak untuk proses metabolisme tubuhnya. Faktor dalam umumnya adalah faktor yang sukar dikontrol, diantaranya ialah keturunan, sex, umur, parasit dan penyakit (Effendie, 1997). Sedangkan faktor luar yang utama mempengaruhi pertumbuhan ialah makanan dan suhu perairan (Effendie, 1997). Suhu yang rendah akan menyebabkan kurangnya nafsu makan ikan, ikan menjadi lamban berkembang dan tubuh kecil yang akhirnya ikan tersebut sering berenang menyendiri. Menurut Rounsefeel and Everhart, (1953) suhu yang rendah menyebabkan rendahnya pertumbuhan biota perairan, demikian juga apabila suhu tinggi. Hal ini menyebabkan proses pencernaan makanan pada ikan berlangsung lambat, secara tidak langsung suhu akan mempengaruhi pertumbuhan ikan.

Energi yang berasal dari pakan selain dipergunakan untuk pertumbuhan juga dipergunakan untuk proses metabolisme dalam tubuhnya, sehingga pertumbuhan ikan tidak berlangsung secara optimal. Hal ini didukung sesuai pernyataan Fujaya, (2008) bahwa tidak semua makanan yang dimakan oleh ikan digunakan untuk pertumbuhan. Sebagian besar energi dari makanan digunakan untuk metabolisme basal (pemeliharaan), sisanya digunakan untuk aktivitas, pertumbuhan, dan reproduksi. 
Sampling ke 3 dan ke 4 , pertumbuhan panjang serta berat benih ikan Patin Siam mengalami peningkatan pertumbuhan. Benih ikan Patin Siam di fase ini telah berumur 25 hari dan telah mengkonsumsi pakan pelet. Pada sampling benih ikan Patin Siam berumur 25 hari, didapatkan pertumbuhan panjang rata-rata perlakuan A 3,14 $\mathrm{cm}$, perlakuan B $3,48 \mathrm{~cm}$, perlakuan $\mathrm{C} 3,92 \mathrm{~cm}$, dan perlakuan D $3,83 \mathrm{~cm}$. Pertumbuhan rata-rata berat setiap perlakuan yaitu perlakuan A rata-rata berat benih mencapai 0,222 gram, sedangkan ratarata berat perlakuan $B$ mencapai 0,385 gram. Perlakuan C mencapai 0,526 gram, dan perlakuan D 0,472 gram.

Benih ikan Patin Siam pada sampling diumur 35 hari mempunyai nilai pertumbuhan berat rata-ratanya yaitu perlakuan A sebesar 0,645 gram, perlakuan B sebesar 0,877 gram, perlakuan C sebesar 1,411 gram, dan perlakuan D sebesar 1,069 gram. Sedangkan panjang rata-rata perlakuan A sebesar 4,30 cm, perlakuan B sebesar $4,69 \mathrm{~cm}$, perlakuan C sebesar 5,43 cm, perlakuan D 4,95 cm. Diduga pada saat umur tersebut ikan telah mengalami fase penyesuaian terhadap lingkungan. Pada Sampling pertumbuhan berat pada umur 25 hari sampai 35 hari mengalami kenaikan pertumbuhan. Ini dikarenakan benih ikan telah mengalami proses pertumbuhan yang memang memanfaatkan energi dari sumber makanan. Sesuai dengan pernyataan (Fujaya, 2008) ikan muda yang sedang tumbuh lebih banyak menggunakan energi persatuan berat badannya dibandingkan ikan dewasa, karena energi dibutuhkan tidak saja aktifitas dan pemeliharaan tetapi juga untuk pertumbuhan.

Brown (1979) dalam Armila (2000) menyatakan bahwa peningkatan suhu air akan diiringi oleh peningkatan laju metabolisme yang disebabkan karena meningkatnya konsumsi pakan sehingga meningkatnya pertumbuhan ikan. Pertumbuhan panjang mutlak rata-rata pada akhir pemeliharaan, perlakuan $\mathrm{A}$ adalah $3,00 \mathrm{~cm}$, perlakuan B sebesar 3,39 cm, perlakuan C sebesar $4,13 \mathrm{~cm}$, dan perlakuan D sebesar $3,65 \mathrm{~cm}$. Berat mutlak rata-rata pada akhir pemeliharaan, perlakuan A adalah 0,63 gram, perlakuan B sebesar 0,87 gram, perlakuan C sebesar 1,39 gram, perlakuan D sebesar 1,05 gram. Berdasarkan BSN, (2000.b) panjang total benih ikan Patin Siam yang berumur 15 hari adalah 0,75 inchi $(1,9 \mathrm{~cm})$ dan benih patin siam yang berumur 36 hari adalah $1,0-$ 2,0 inchi $(2,54-5,08 \mathrm{~cm})$, sedangkan berat total benih patin siam yang berumur 36 hari adalah 1,0 3,0 gram.

Selama pemeliharaan benih ikan Patin Siam setiap perlakuan ada yang ukuran panjang dan beratnya tidak seragam. Ini dikarenakan benih ikan tersebut lamban dalam merespon makanan serta terjadinya persaingan dalam memperoleh makanan tersebut. Menurut Fujaya (2008) terlalu banyak individu dalam perairan yang tidak sebanding dengan keadaan makanan akan terjadi kompetisi terhadap makanan itu. Benih ikan yang kurang respon terhadap pakan yang diberikan akibat dari kurang beradaptasinya terhadap lingkungan. Hal ini menyebabkan benih ikan tersebut mengalami keterlambatan pertumbuhan, sehingga benih ikan yang sukar memakan pakan yang diberikan tersebut ukurannya menjadi berbeda dibandingkan benih lain yang dapat bersaing dalam memperoleh makanan. Keberhasilan mendapatkan makanan akan menentukan pertumbuhan, oleh karena itu dalam satu keturunan akan didapatkan ukuran bervariasi (Fujaya, 2008).

\section{Kualitas Air}

Kisaran data parameter kualitas air meliputi suhu, $\mathrm{pH}$, dan oksigen terlarut (DO) selama pemeliharaan dapat dilihat pada Tabel 1

Tabel 1. Data Parameter Kualitas Air

\begin{tabular}{cccc}
\hline Perlakuan & \multicolumn{3}{c}{ Parameter } \\
\cline { 2 - 4 } & Suhu $\left({ }^{\mathbf{C}} \mathbf{C}\right)$ & $\mathbf{p H}$ & $\begin{array}{c}\text { DO } \\
(\mathbf{m g} / \mathbf{L})\end{array}$ \\
\hline A & $25,4-26,8$ & $6,30-7,30$ & $3,10-3,39$ \\
B & $27,7-28,8$ & $6,22-6,24$ & $3,02-3,27$ \\
C & $29,5-30,8$ & $6,07-6,10$ & $2,05-3,06$ \\
D & $31,4-32,3$ & $6,28-6,38$ & $2,35-2,79$ \\
\hline
\end{tabular}

Parameter kualitas air selama 30 hari pemeliharaan, yang diukur selama penelitian masih dalam batas kemampuan toleransi untuk pertumbuhan Ikan Patin Siam (Pangasius hypophthalmus). Suhu pada perlakuan A berkisar antara $25,4-26,8^{\circ} \mathrm{C}$, perlakuan B berkisar $27,7-28,8$ ${ }^{\circ} \mathrm{C}$, perlakuan $\mathrm{C}$ berkisar 29,5-30,8 ${ }^{\circ} \mathrm{C}$, dan perlakuan D berkisar $31,4-32,3{ }^{\circ} \mathrm{C}$. Tancung dan Kordi (2007) dalam Yuli (2017) menyatakan bahwa pada umumnya metabolisme ikan mempunyai hubungan erat dengan temperatur atau suhu air. Metabolisme yang paling baik terjadi pada saat temperatur tertinggi dikisaran normal.

Suhu berperan penting terhadap berlangsungnya pertumbuhan ikan. Suatu aktivitas metabolisme ikan berbanding lurus terhadap suhu air. Semakin tinggi suhu air semakin aktif pula metabolisme ikan, demikian pula sebaliknya. Kondisi suhu sangat berpengaruh terhadap kehidupan ikan. Pada suhu rendah, ikan akan kehilangan nafsu makan dan menjadi lebih rentan terhadap penyakit. Sebaliknya jika suhu terlalu tinggi maka ikan akan mengalami gangguan pernapasan dan bahkan dapat menyebabkan kerusakan insang permanen (Jaya, 2011).

Suhu air mempercepat reaksi kimia, baik dalam media luar maupun air (cairan) dalam tubuh ikan. Suhu makin naik maka reaksi kimia akan semakin cepat, sedangkan konsentrasi gas dalam 
air akan semakin menurun termasuk oksigen. Akibatnya, ikan akan membuat reaksi toleran atau tidak toleran (sakit sampai kematian). Putri et al (2019), suhu dapat meningkatkan laju metabolisme dalam tubuh yang membuat tingkat kelangsungan hidup ikan. Menurut Wihardi et al (2014), suhu air sangat mempengaruhi laju pertumbuhan, laju metabolisme ikan dan nafsu makan ikan serta kelarutan oksigen dalam air. Untuk menghadapi perubahan kondisi lingkungan demikian, diperlukan kemampuan adaptasi fisiologis secara optimal untuk mempertahankan atau mencapai kemampuan hidup (Petrus, 1999 dalam Reinnamah, 2010). Suhu air selama pemeliharaan masih dibatas toleransi, hal ini ditunjang menurut BSN (2000.c) kisaran suhu pemeliharaan benih ikan Patin siam adalah $27-30^{\circ} \mathrm{C}$.

Nilai pH selama pemeliharaan benih ikan patin siam berkisar antara 6,07-7,30. Pada perlakuan A nilai $\mathrm{pH}$ nya berkisar antara 6,30-7,30, perlakuan B berkisar antara 6,22-6,24, perlakuan C berkisar antara 6,07-6,10, dan perlakuan D berkisar antara 6,28-6,38. Selama pemeliharaan $\mathrm{pH}$ pada media hidup ikan masih dalam batas toleransi untuk pertumbuhan ikan. Perubahan $\mathrm{pH}$ secara perlahan akan menyebabkan lendir keluar berlebihan, kulit menjadi keputihan dan mudah terkena bakteri (Yunias, 2010). Menurut Haris dan Yusanti (2019), jika pH rendah (keasaman tinggi) kandungan oksigen terlarut akan berkurang. Akibatnya, konsumsi oksigen menurun, aktivitas pernafasan naik dan selera makan akan berkurang, pertumbuhan ikan akan terhambat dan ikan rentan terkena bakteri dan parasit, bahkan bisa terjadinya kematian pada ikan

Pada awal penelitian nilai $\mathrm{pH}$ cenderung bersifat basa, pada perairan basa pertumbuhan ikan juga cenderung lambat. Selama pemeliharaan benih ikan Patin Siam nilai pH berkisar antara 6,07-7,30. Pada perlakuan A nilai $\mathrm{pH}$ nya adalah 6,30-7,30, perlakuan $\mathrm{B}$ adalah $6,22-6,24$, perlakuan $\mathrm{C}$ adalah 6,07-6,10, dan perlakuan D adalah 6,28-6,38. Boyd (1982) menyatakan bahwa perairan dengan nilai $\mathrm{pH} 5$ - 6,5 pertumbuhan ikan akan lamban dan reproduksi tidak akan berlansung tetapi untuk kelayakan untuk hidup masih ada. Menurut BSN (2000.c) kisaran derajat keasaman (pH) untuk pemeliharaan benih ikan Patin Siam adalah 6,5 8,5 .

Untuk nilai Oksigen terlarut saat pemeliharaan masih dalam batas toleransi berkisar antara 2,05-3,39 $\mathrm{mgL}^{-1}$. Ikan sebagai salah satu jenis organisme air juga membutuhkan oksigen agar proses metabolisme dalam tubuhnya berlangsung. Oksigen terlarut adalah oksigen dalam bentuk terlarut didalam air. Ikan tidak dapat mengambil oksigen dalam perairan dari difusi langsung dengan udara. Oksigen terlarut saat pemeliharaan masih dalam batas toleransi berkisar antara 2,05-3,39 $\mathrm{mgL}^{-1}$. Pada media pemeliharaan ikan yang kandungan oksigen terlarutnya berada pada kisaran 1-5 mg/l ikan akan dapat bertahan hidup, namun pertumbuhannya lambat jika dibiarkan lama (Boyd, 1982). Menurut BSN(2000.c) bahwa kisaran oksigen terlarut untuk pemeliharaan benih ikan Patin Siam adalah >5 $\mathrm{mg} / \mathrm{l}$.

\section{KESIMPULAN DAN SARAN}

\section{Kesimpulan}

Dari hasil penelitian yang telah dilakukan selama 30 hari pada benih ikan Patin Siam (Pangasius hypophthalmus) dari umur 6 hari sampai umur 35 hari dapat disimpulkan bahwa kelangsungan hidup benih yang terbaik adalah pada perlakuan $\mathrm{C}$ (suhu media pemeliharaan $30 \pm 0,8^{\circ} \mathrm{C}$ ) yaitu sebesar 86,5\% dan pertumbuhan panjang mutlak rata-rata sebesar $4,13 \mathrm{~cm}$ dengan pertumbuhan berat mutlak rata-rata sebesar 1,39 gram

\section{Saran}

Perlu dilakukan penelitian lebih lanjut untuk mengatahui bagaimana pengaruh suhu terhadap pertumbuhan, dan kelangsungan hidup pada benih ikan Patin Siam (Pangasius hypophthalmus)

\section{DAFTAR PUSTAKA}

Badan Standarisasi Nasional (BSN). 2000.c. Standar Produksi Benih Ikan Patin Siam. Standar Nasional Indonesia. 01-6483.42000.

Effendie, 1997. Metode Biologi Perikanan. Yayasan Pustaka Nusantara, Yogyakarta.

Effendie, M.I. 2002. Biologi Perikanan. Yayasan Pustaka Nusatama. Yogyakarta.

Fujaya, Y. 2008. Fisiologi Ikan Dasar Pengembangan Teknik Perikanan. ineka Cipta. Jakarta.

Hamid, M., A. dan Setyowibowo, C. 2010 Manual Pembenihan Patin Siam (Pangasius hypophthalmus). BBAT Jambi.

Hanafiah, K. A. 2005. Teori dan Aplikasi Rancangan Percobaan. Raja Grafindo Persada. Jakarta.

Haris RBK, Nurbambang A, Anggoro S. 2017. Analisis Prospek Pengembangan Usaha Pembesaran Ikan Bandeng (Chanos chanos Forskal 1775) di Kecamatan Tugu Kota Semarang Provinsi Jawa Tengah. Jurnal Ilmiah Agr IBA. 5(1): 70-83

Haris, R.B.K dan Yusanti, I.A . 2019. Analisis Kesesuaian Perairan untuk Keramba Jaring Apung di Kecamatan Sirah Pulau Padang Kabupaten Ogan Komering Ilir Provinsi 
Sumatera Selatan. Journal of Suboptimal Lands.8(1) : 20-30

Huet, M. 1971. Textbook of Fish Culture. Breeding and Cultivation of Fish. Fishing New Book, Ltd., London.

Jaya, R. 2011. Hubungan Parameter Kualitas Air Dalam Budidaya Ikan Nila. Skripsi, Manajemen Sumberdaya Perairan Fakultas Pertanian Universitas Negeri Musamus Merauke (tidak dipublikasikan).

Khairuman. 2002. Budidaya Patin Super. Agromedia. Jakarta.

Putri, W.R. Harris, H., dan Haris, R.B.K. 2019. Kombinasi Maggot pada Pakan Komersil terhadap Pertumbuhan, Kelangsungan Hidup, FCR dan Biaya Pakan Ikan Patin Siam (Pangasius hypophthalmus). Jurnal
Ilmu-ilmu Perikanan dan Budidaya Perairan. 14(1) : 7-16.

Wihardi, Y., Yusanti, I.A dan Haris, R.B.K. 2014. Feminisasi pada Ikan Mas (Cyprinus carpio) dengan Perendaman Ekstrak Daun-Tangkai Buah Terung Cepoka (Solanum torvum) pada lama Waktu Perendaman Berbeda. Jurnal Ilmu-ilmu Perikanan dan Budidaya Perairan. 9(1) : $23-28$.

Yuli, S., Harris, H., Yusanti, I. A. 2017. Tingkat Serangan Ektoparasit pada Ikan Patin (Pangasius Hypopthalmus) yang Dibudidayakan dalam Keramba Jaring Apung di Sungai Musi Palembang. Jurna IIlmu - ilmu Perikanan dan Budidaya Perairan. 12(2) : 50-58

Yunias. 2010. Pengukuran Kualitas Air Tambak. Jakarta. 
Jurnal Ilmu-ilmu Perikanan dan Budidaya Perairan Volume 14, Nomor 2, Desember 2019 